\title{
Research and Analysis on the Status Quo of and Countermeasures for Professional Taekwondo Athletes in Southwest China Mainly in Sichuan and Chongqing
}

\author{
Xiaoyuan Wen \\ Chengdu Sports University
}

\begin{abstract}
It was in 1994 that Taekwondo was officially introduced into China. After that, Taekwondo was put on the list of China's Ninth National Sports Games. Just a few years, China achieved so outstanding results in the Olympic Games as to promote Taekwondo's rapid development in China. The development during the twenty years made Taekwondo all the way from weak to strong, into the ranks of the top sports. The rapid development of Taekwondo in China also attracted the attention of provincial and Municipal Sports Bureau to build various provincial or city team. Compared to the rapid development of the athletic level in other regions of China, the development in the southwest area is relatively slow. The southwest area refers to Chongqing, Guizhou, Sichuan, Yunnan, Tibet. At present, from the overall perspective, the development of the athletic sports in southwest area is much slower than east coastal area, no matter the athletic performance or the idea of development. In order to speed up the scientifization, systematization and standardization of Taekwondo's development and promote its athletic level, We practiced investigation, questionnaire investigation, experience and interview based on the present situation of Sichuan and Chongqing professional Taekwondo Athletes in southwest area to understand why the Taekwondo's athletic levels is relatively lower than coastal area.
\end{abstract}

Keywords-southwest area, mainly in Sichuan and Chongqing, Taekwondo athletes, Status quo, countermeasures

\section{PREFACE}

Taekwondo is the national sport of Korea. "Tae-" means the skills for the use of the foot to attack, defense and do pas de cheval, "-kwon-"is the skills for the use of hand or fist to attack and defense, "-do" carries the meaning of practicers' cultivation of mind to martial arts and its correction. On April 11, 1955, the Committee composed of South Korea famous peoplem different fields, including major general Cui Hongxi (South Korea's the third armed force commander), major general $\mathrm{Li}$ Xianggen (national military joint chief), deputy speaker of Parliament, members of Congress, famous entrepreneurs, famous curator etc. put forward their ideas of the name. After the anonymous votes, the committee adopted the general Cui Hongxi's idea-- "Taekwon". Thus, it became taekwondo. Since then, it ended the era of Tang hand, Empty hand and various classical Korean martial names. North Korea's martial arts created a new world, and taekwondo started its history. On March, 1959, the Korean National Taekwondo organization went abroad for the first time, introduced Taekwondo to foreign countries. The 24th Olympic Games in 1988 hold in Korea kicked off in Seoul, the host country made unremitting efforts to put taekwondo on the list of the 24th, 25th and 26th Olympic Games performance projects which provided the greatest opportunity and motive force for the rapid development of taekwondo. In 1994, the 103rd International Olympic Committee session held in Paris decided that taekwondo would be the official game in the 2000 Olympic games. China formally developed Taekwondo in 1994. The athletic level is the reflection of one region's comprehensive strength and social civilization, and also a key factor to promote the development of sports. This paper is mainly to provide reference for the better development of Taekwondo in southwest region by investigating and analyzing the status quo of Taekwondo athletes in the southwest area.

\section{TAEKWONDO DEVELOPMENT IN SOUTHWEST OF CHINA}

It has been 20 years since Taekwondo was formally introduced into China. Compared with other areas in China, the southwest Taekwondo started slightly later. Due to many reasons like geographical constraints and social, economic factors, there is always a certain gap between China's middle-east athletic sports and southwest area. Sichuan province and Chongqing, as the representatives in the southwest area, play a leading role. Sichuan's and Chongqing's Taekwondo team were founded in 1996 and 1997. And they have gone through a bumpy development history. From the current competitive level, the competitive strength of Sichuan province Taekwondo team is in a leading position after several years of development, but the individual competitive ability and level are not very stable. Chongqing city Taekwondo team's group or individual athletics level are relatively backward compared with Sichuan Taekwondo Team. To narrow the gap between the two teams is to improve the overall competitive level of southwest area. Therefore, we need to deeply understand the current development of Taekwondo professional athletes in the southwestern region(mainly in Sichuan and Chongqing), to cautiously analyze the related factors of the competitive level of Taekwondo in southwest area, to reveal the problems of Taekwondo development in southwest area. This paper analyzes main factors restricting the improvement of Taekwondo's competitive level in southwest area mainly through the research and 
investigation of professional Taekwondo athletes' status quo in southwest area (mainly in Sichuan and Chongqing).

\section{ANALYSIS ON THE BASIC INFORMATION OF SICHUAN PROVINCE'S AND CHONGQING'S TAEKWONDO ATHLETES}

The questionnaire of 50 professional Taekwondo athletes summarizes the athletes' age and grade structure, years of training, training background characteristics, annual state of contestants, training time and education background, and analyzes the main problems existing in the southwest area for Taekwondo athletes.

\section{A. Analysis on the Athletes' Age Structure}

Age is an important factor for selecting sports talent. Suitable age has strong links with athletic training, it is related to the talents selection, talents developing, talents establishing and qualitative effects [1]. The athletes' training is a long-term plan and a big project. Taekwondo belongs to skill fighting projects, it is a sport that technical and tactical ability is the dominant factor to the athlete, a weapon for winning. The characteristics of this sport is that the athletes must start general physical fitness training at a very young age, and then the special physical quality training; at last, an excellent athlete will be developed after a series of actual competition and large important hone [2].

TABLE 1 THE STATISTICS OF THE AGE STRUCTURE OF THE TAEKWONDO ATHLETES IN SICHUAN AND CHONGQING

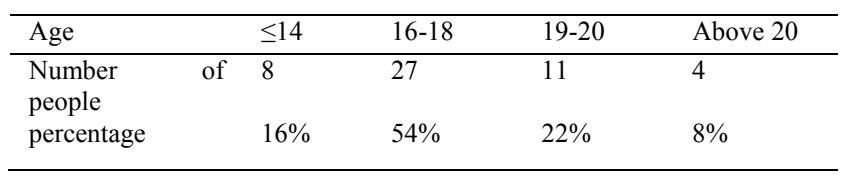

Table 1 says that the professional Taekwondo athletes whose age are mainly 16 to 18 take up $54 \%$ of the surveyed; then whose age is $19-20$ take up $22 \%$; whose age is under 14 take up 16\%; whose age is above 21 take up only $8 \%$. The conclusion would be that most of the Taekwondo athletes in southwest area are 16-18 years old which is the period of rapid development.

\section{B. Analysis on the Athletes' Grade Structure}

TABLE 2 THE STATISTICS OF THE GRADE STRUCTURE OF THE TAEKWONDO ATHLETES IN SICHUAN AND CHONGQING

\begin{tabular}{|c|c|c|c|c|c|}
\hline Grade & & Elite & $\begin{array}{l}\text { National } \\
\text { Level } 1\end{array}$ & $\begin{array}{l}\text { National } \\
\text { Level } 2\end{array}$ & $\begin{array}{l}\text { No } \\
\text { Grade }\end{array}$ \\
\hline $\begin{array}{l}\text { Number } \\
\text { people } \\
\text { percentage }\end{array}$ & of & $\begin{array}{l}5 \\
10 \%\end{array}$ & $\begin{array}{l}16 \\
32 \%\end{array}$ & $\begin{array}{l}9 \\
18 \%\end{array}$ & $\begin{array}{l}20 \\
40 \%\end{array}$ \\
\hline
\end{tabular}

Table 2 says that in Sichuan and Chongqing there are 5 elites who take up $10 \%$ of the surveyed; 16 National Level 1 sportsmen who take up 32\%; 9 National Level 2 sportsmen who take up $18 \%$ and those who have no grade take up $40 \%$. The percentage of elites is quite low and most of the athletes have no grade, which indicates that they are immature groups with little competition experience, Sichuan and Chongqing still need to increase the intensity of training high-level athletes.

\section{Analysis on the Athletes' Years of Training}

TABLE 3 THE STATISTICS OF THE YEARS OF TRAINING OF THE TAEKWONDO ATHLETES IN SICHUAN AND CHONGQING

\begin{tabular}{lllll}
\hline Years of Training & $1 \leq$ & $2-3$ & $4-5$ & $>6$ \\
\hline Number of people & 9 & 13 & 21 & 7 \\
percentage & $18 \%$ & $26 \%$ & $42 \%$ & $14 \%$ \\
\hline
\end{tabular}

Table 3 showed that in Sichuan and Chongqing those professional taekwondo athletes aged between 16-18 who have $4-5$ years of training take up $42 \%$ of the surveyed. From the whole perspective, they are lack of experience. To achieve a certain athletic level, athletes must have appropriate training years and competition experience. Research materials proposed that the time for reaching different performance levels is relatively stable, eg. one level to a higher level needs 1 to 2.5 years on average [1]. It is a gradual, continuous improvement process to master the athletic skills. Taekwondo skills and tactics are complex and diverse, raising the level of the youth requires a long-term process, enough time, continuous competition practice and the accumulated experience from coaches and repeated individual race.

\section{Analysis on the Athletes' Training Background Characteristics}

Sports talents developing and training system in China is from former Soviet, taking the "Junior Amateur Sports School in counties---- Provincial Sports School (professional teams) ---- national team" as the particular routine for talents cultivation. Athletes are the essential part of sport. Laying solid foundation for good seeds is related to the fundamental guarantee of reserve talents training and sustainable development [3]. Although Taekwondo in the Southwest started late, it still is having rapid development while facing various problems. Mass base is weak, the technical and tactical skills are poor, the skeleton coaches have low professional qualities. All of this restricted the developing and delivery of sports elites. Some scholars conducted communication with the world, study the scientific theory and improve the relationship researches on mass Taekwondo and athletic Taekwondo and believing that to promote the development of Taekwondo in China, we must modify the various teams, reinforce the between the mass and athletics[4].

TABLE 4 THE STATISTICS OF THE TRAINING BACKGROUND OF THE TAEKWONDO ATHLETES IN SICHUAN AND CHONGQING

\begin{tabular}{llll}
\hline $\begin{array}{l}\text { Training } \\
\text { Background }\end{array}$ & Self-Developing & $\begin{array}{l}\text { Tournament } \\
\text { Selection }\end{array}$ & $\begin{array}{l}\text { Developed by } \\
\text { local } \\
\text { government }\end{array}$ \\
\hline $\begin{array}{l}\text { Number of } \\
\text { people } \\
\text { percentage }\end{array}$ & 3 & 19 & 28 \\
\hline
\end{tabular}


Table 4 says that the main way for developing Taekwondo athletes is by the local government's support, which shows that the selection of the reserve talents is in a inactive position. Taekwondo teams should develop athletes and dig the potential talents on their own, they should establish their own teams to maintain the sustainable development of Taekwondo in southwest area.

\section{E. Analysis on the Annual State of Contestants}

TABLE 5 THE STATISTICS OF THE ANNUAL STATE OF TAEKWONDO CONTESTANTS IN SICHUAN AND CHONGQING

\begin{tabular}{llll}
\hline Competition times each year & $1 \leq$ & $2-3$ & $>4$ \\
\hline Number of people & 17 & 27 & 6 \\
percentage & $34 \%$ & $54 \%$ & $12 \%$ \\
\hline
\end{tabular}

Table 5 shows that those athletes who participate in the competition 2-3 times a year take up 54\%, followed by one time or none, $34 \%, 12 \%$ for those four times or more. From the whole perspective, only few athletes participate more than four times and their performance is not very satisfactory. $54 \%$ of the athletes participate in a very formal race one time a year at most. Those data sufficiently explains the relative lack of Taekwondo competitions in southwest area, not mention the high-standard competition, so as to there are only few opportunities to participate a formal competition for athletes in southwest area, only good or top athletes have the chance to participate in a competition, most of the players are just blindly trained, they do not have the opportunity to personally experience the game, therefore, they will be lack of combat ability, which is neither conducive to improve their performance, nor good to strengthen their enthusiasm for training. This is how the athletic level in southwest area has been affected.

\section{F. Analysis on the Athletes' Training Time and Education Background}

Athletes are the essential part of the sport. It is a gradual, continuous improvement process to master the athletic skills. Taekwondo skills and tactics are complex and diverse, raising the level of the youth requires a long-term process and sufficient training time. Moreover, reasonable training frequency and time should be arranged to guarantee a scientific and systematic training. Taekwondo teams surveyed in Chongqing and Sichuan, they have six days a week for training, twice a day at average and 4-6 hours a day at average, which shows that training time can be basically guaranteed. They mainly focus on training instead of cultural education, as long as the athletes achieve good score in sport, leading to the result that athletes have poor theoretical foundation. Currently sports management department ignore the athletes' education in some way, which means their measures for education are ineffective, teaching management is lax, quality of education is low. It directly leads to the athletes' low education quality in general. On one hand, it also restricts the improvement of the athletes skills; on the other hand, it brought big problems to settle the athletes after their retirement. As a result, the amateur training selection becomes rather difficult.

\section{G. Life Security for the Athletes Present Situation and Their Retirement}

Training and security conditions can be regarded as the fundamental support system for sustainable development of the athletic reserve talents, and the supportive power to the system's survival and development. With the support and attention from the relevant policies, meanwhile with the economic support and site support, it provides athletes a reliable insurance. By research, Taekwondo athletes after retirement, some of whom can work as part-time coaches, some can go to sports schools, or be a security guard, but the majority don't have a solution.

\section{SUGGESTIONS FOR TAEKWONDO DEVELOPMENT IN THE SOUTHWEST AREA}

\section{A. To Create A Good Competition Condition and Hold More Competition, To Strengthen the Communication with Outside and Improve Athletes' Skill}

At present, the athletes in the southwest area have few opportunities to participate in the games every year and to communicate with others in high-standard competitions, which will inevitably depress the athletes' enthusiasm for training. Therefore, the chances should be created for those second-line athletes to discover more good reserve talents when the first-line athletes have been guaranteed to participate. The relevant Southwest Region authorities should reform the existing system of taekwondo competition, increase the number of the local games or real exchange competition to promote training and to improve combat capability on the spot. This could provide the majority opportunities to participate games to achieve equality for all. Relevant government departments should favorite some backward areas with policies to promote the development of the sport in the native region; one team should invite other teams or different provincial teams to share ideas, exchange and learn from each other through the games, which is helpful to find out training deficiencies. It is the only way to create a high-level training and competition environment and improve the training results. Athletes should seize the opportunity to actively participate in those high-level competitions so that the athletes can improve their athletic record and gain experience through mutual learning. The organized competition should be constantly improved so that the athletes will give full play and have a higher participation in the competition, also the entire southwest region of Taekwondo competitive level will be improved.

\section{B. To strengthen the Cultivation of the Athletes' Education}

Affected by the long-term development of competitive sports, the cultivation of competitive talents' education has been ignored. Young athletes' knowledge level is not only an important basis for developing athletes' 
intelligence level, but also the important foundation of improving the Taekwondo athletes' technical and tactical skills. And nevertheless, it is very important for the young athletes to be competent for their future work. Physical education should be arranged rationally, the education system and physical education system should cooperate with each other, the multi-level and the integration of training system for the reserve talents should be established. Coaches should implement the management on athletes' study and encourage the athletes to focus on cultural learning and physical training at the same time, they also should create a good learning atmosphere to influence the athlete's cultural accomplishment and guarantee a sustained, healthy and comprehensive development for the reserve talents which lays a solid foundation for the athletes' settlement after retirement.

\section{To Reinforce the Storage and Cultivation of Reserve Talents and Establish a Set of Incentive Mechanism}

It is necessary to strengthen the relations among those various amateur training and build up a harmonious talents supply system. The Heavy Athletics Management Center should reinforce management, improve the management mechanism and positively mobilize the City Sports Bureaus' attention on taekwondo. We should take the go-out policy that leads us to the areas with good sport foundation to select talents. In order to improve the athletic level of Southwest Taekwondo, the current situation of southwest area needs us to implement different degrees of reward system, and to reward participants who had outstanding achievements in a competition. Meanwhile, we should improve the living material security for the athletes. Other relevant policies and regulations of the medical insurance for elite athletes and the resettlement for retired athletes should be formulated, contacts with all kinds of colleges and universities should be made, the back-plan for athletes should be broaden to solve any menace for them.

\section{REFERENCES}

[1] Wong Jincan. The Science of Sport Material [M]. Beijing: People's Sport Press, 2009

[2] Li Ning. The Obstacles and Countermeasures of Jiangxi Province Achieving Taekwondo Gold Medal in the Tenth National Games [D]. 2004, 11.

[3] Zhang Zhiwei. Research and Analysis on the Present Situation and Countermeasures of Developing Reserve Talents(age between 10 and 16) for Hebei Province's Tabletennis [D]. Beijing Sport University, 2004, 4:14.

[4] Sun Maojun, Liu Weijun. Analysis on the Development and Countermeasures of Taekwondo in China [J]. Journal of Capital $\begin{array}{lllll}\text { Sport } & \text { College. } & 2005, & 17 & \text { (1): }\end{array}$ 